\title{
Experience of dysmenorrhea among a group of physical therapy students from Cairo University: an exploratory study
}

This article was published in the following Dove Press journal:

Journal of Pain Research

9 May 2017

Number of times this article has been viewed

\section{Dalia M Kamel ${ }^{1,2}$}

Sayed A Tantawy 2,3

Gehan A Abdelsamea'

'Department of Physical Therapy for Obstetrics \& Gynecology,

Faculty of Physical Therapy, Cairo University, Giza, Egypt; ${ }^{2}$ Physiotherapy Department, College of Medical and Health Sciences, Ahlia University, Manama, Kingdom of Bahrain; ${ }^{3}$ Department of Physiotherapy, Centre of Radiation, Oncology and Nuclear Medicine, Cairo University, Giza, Egypt

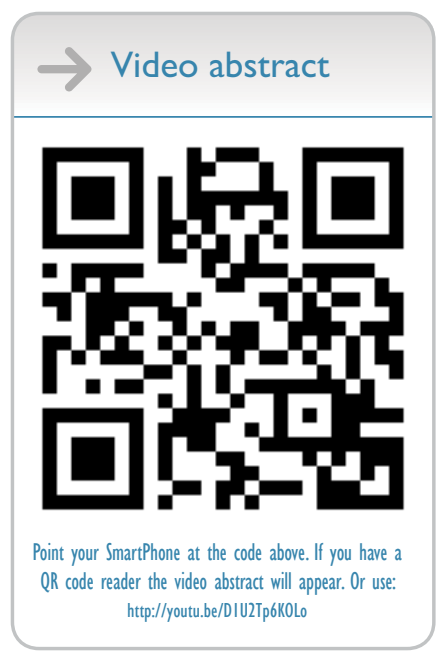

Correspondence: Dalia M Kamel Department of Physical Therapy for Obstetrics \& Gynecology, Faculty of Physical Therapy, Cairo University, P.O. Box 12612, Giza, Egypt

Tel +2023748 2979

$\mathrm{Fax}+20237617692$

Email dr_daliakamel@yahoo.com
Introduction: Dysmenorrhea is a condition describing the painful cramps that women feel before or during the menstrual period. While dysmenorrhea is the most common gynecologic complaint affecting adolescent and young women and there has been significant progress in understanding its pathophysiology and managing the symptoms, many young women do not seek medical consultation and remain untreated.

Aim of the study: The aim of the study was to explore the prevalence of dysmenorrhea, its physical impact, and associated coping behaviors among university students.

Methods: A total of 269 female college students volunteered to participate in the study. Data regarding the students' experience with dysmenorrhea were collected via self-reported questionnaire developed based on relevant literature. Pain was scored on visual analog scale (VAS). Results: Most respondents $(84.01 \%)$ reported feeling pain in the abdomen and back (VAS score, 5.00). Mood swings (84.8\%) and dizziness (48.2\%) were, respectively, the most common affective and somatic symptoms related to menstruation. There was a significant difference in the amount of menstrual flow $(p=0.004)$ and incidence of dysmenorrhea $(p=0.03)$ according to menstrual regularity. Most students $(91.2 \%)$ did not seek medical consultation for dysmenorrhea, and $62.4 \%$ used analgesics. However, no significant correlation $(p=0.25)$ was found between analgesic intake and pain relief. While most students $(90.7 \%)$ did not miss exams, $48.7 \%$ reported poor satisfaction with their academic performance because of dysmenorrhea. Conclusion: Dysmenorrhea is highly prevalent among college students, with many physical impacts and associated activity limitations. Collaborative efforts from health care providers, program coordinators, and parents should focus on increasing awareness and improving management strategies to treat dysmenorrhea.

Keywords: dysmenorrhea, prevalence, treatment, physical impact, menstrual cycle

\section{Introduction}

While dysmenorrhea is a very common gynecologic problem that affects women in the reproductive age, awareness among young women is very low. ${ }^{1,2}$ There are two main types of dysmenorrhea, namely, primary and secondary. This research was concerned with primary dysmenorrhea (PD), which usually begins during adolescence and is defined as painful menses in women with normal pelvic anatomy. ${ }^{3}$ These painful menses are colicky in character and typically located in the mid area of the lower abdomen, but may extend to the lumbar area and inner thighs. Dysmenorrhea has other associated symptoms such as nausea, vomiting, diarrhea, headache, and back pain., ${ }^{4,5}$ Many young women discuss painful menses and associated symptoms with their mothers and friends rather than with health care providers. ${ }^{6}$ Hence, dysmenorrhea-coping behaviors 
mostly involve traditional rather than formal health care. ${ }^{6,7}$ The prevalence of PD was investigated in different parts of the world and was found to vary with the geographical location. Specifically, the prevalence of PD was reported at $87.8 \%$ and $72.7 \%$ among university students in Turkey, ${ }^{8,9}$ $89.1 \%$ in Iran, ${ }^{10} 65 \%$ in India, ${ }^{11} 76 \%$ in Malaysia, ${ }^{12}$ and $60 \%$ in Canada. ${ }^{13}$ In Arab countries such as Oman, Iraq, Lebanon, and Saudi Arabia, the reported prevalence of PD was 94\%, ${ }^{14}$ $89.4 \%,{ }^{15} 74.3 \%,{ }^{16}$ and $60.9 \%$, respectively. ${ }^{17}$ In Egypt, which is a large country in terms of land area and population size, the prevalence of dysmenorrhea was examined only in two districts, and studies have reported a prevalence of $76.1 \%$ and 90.4\% among secondary school girls and nursing university students in Asyut, respectively, ${ }^{18,19}$ compared with $75 \%$ and $78.8 \%$ among general and technical secondary school girls in Mansoura, respectively. ${ }^{20,21}$ Taken together, these findings clearly indicate that dysmenorrhea represents a common complaint in various populations. Since the Faculty of Physical Therapy of Cairo University accepts students from different parts of Egypt, it is expected that sampling such a population of students would provide a nationwide view of the students' experience with dysmenorrhea. Therefore, the aim of this study was to investigate the prevalence and physical impact of dysmenorrhea among female college students.

\section{Methods}

\section{Study design and subjects selection}

This survey was approved by the Research Ethical Committee of the Faculty of Physical Therapy of Cairo University (No P.T. REC/ 012/001428). Between August 2015 and March 2016, the study randomly recruited women studying at the Faculty of Physical Therapy. The following inclusion criteria were applied: age, 18-25 years; single; no history of blood disorders including thalassemia and folate or iron-deficiency anemia; absence of chronic illness that may affect the general health. The probabilistic sample size calculation for prevalence was used to calculate the sample size in this study, $n=t^{2} \times p$ $(1-p) / m^{2}$, with $n=$ required sample size, $t=$ confidence level at $95 \%$ (standard value of 1.96), $p=$ estimated prevalence of dysmenorrhea in the study area $(70 \%), m=$ margin of error at $5 \%$ (standard value of 0.05$)$, and $n=(1.96)^{2} \times 0.7(1-0.7) /(0.05)^{2}$. Hence, the required sample size was $n=\sim 323$ participants.

Of the 323 women who received the questionnaire, 54 were excluded from the study because they did not return the questionnaire (30 women), had chronic illness including type 1 diabetes, rheumatoid arthritis, or asthma (16 women), or underwent appendectomy (8 women). The final sample included 269 women who met the inclusion criteria and returned the questionnaire with complete responses. All women provided written informed consent to participate in the study. The questionnaire developed by Potal et $\mathrm{al}^{8}$ was used in this study, with a few modifications (adding or removing questions) to account for specific characteristics of the study sample. The modified self-reported questionnaire was tested by an expert for face and content validity as well as internal consistency, obtaining Cronbach alpha value of 0.71 , which is considered to indicate average to high reliability. The survey included questions that aim to provide an overview of the experience of women with dysmenorrhea. The following data were collected: age at menarche; presence and duration of dysmenorrhea; amount of bleeding; menstruation regularity; source of knowledge regarding menses; associated symptoms; severity of dysmenorrhea in different parts of the body, scored on the visual analog scale (VAS) from 0 to 10 ; and methods used to relieve the pain.

\section{Statistical analysis}

Descriptive statistics included the mean and standard deviation for the participants' age, menarche age, and frequency and duration of their menstruation. The responses to most other questions were described in terms of absolute numbers and frequencies. A nonparametric analysis was performed on the VAS pain scores. The independent sample $t$-test, MannWhitney $U$ test, and Pearson correlation test were used to investigate the differences and correlations among variables such as menarche age, physical activity, and dysmenorrhea. Furthermore, correlations between the amount and duration of the menstrual flow in addition to analgesic use with changes of pain pattern were analyzed.

\section{Results}

The mean age of the participants was $20.4 \pm 1.7$ years, and their mean age at menarche was $12.86 \pm 1.43$ years. The participants' affective and somatic symptoms of menstruation, source of knowledge on menstruation, and home remedies used to control menstrual pain are listed in Table 1. Regarding physical activity level, it was found that 163 women $(60.59 \%)$ regularly engaged in physical activities, such as walking, aerobic exercise, and cardio exercise, whereas 106 women $(39.41 \%)$ had a sedentary lifestyle. No significant correlation ( $r=0.113, p=0.064$ ) was found between physical activity level and incidence of dysmenorrhea. Moreover, no significant difference ( $p=0.314$ ) was found between physically active and sedentary subjects with respect to pain during menstruation.

Regarding menstrual regularity, the results revealed that 206 (76.6\%) and 63 (23.4\%) participants had regular and irregular cycles, respectively. To assess the frequency of the menstrual cycle, the data regarding women with irregular 
Table I Participants' related menstruation major features

\begin{tabular}{|c|c|}
\hline \multicolumn{2}{|l|}{ Menstruation affective symptoms $(n=269)$} \\
\hline Mood swings & $228(84.8 \%)$ \\
\hline Fatigue & $220(81.8 \%)$ \\
\hline Anxiety & $162(60.2 \%)$ \\
\hline Bloated abdominal feeling & $138(5 \mid .3 \%)$ \\
\hline Sadness & $129(47.9 \%)$ \\
\hline Change in sleeping patterns & $105(39.03 \%)$ \\
\hline Loss of appetite & $94(34.9 \%)$ \\
\hline Decrease in concentration & $76(28.3 \%)$ \\
\hline Persistent irritability & $76(27.3 \%)$ \\
\hline Enhanced appetite & $63(23.4 \%)$ \\
\hline \multicolumn{2}{|l|}{ Source of knowledge about menstruation $(n=269)$} \\
\hline Mothers & $198(73.6 \%)$ \\
\hline Nobody & $30(11.2 \%)$ \\
\hline Others (school teacher or based on college study) & $18(6.7 \%)$ \\
\hline Friend/sibling & $12(4.46 \%)$ \\
\hline Physician/nurse & II (4.08\%) \\
\hline \multicolumn{2}{|l|}{ Dysmenorrhea somatic symptoms $(n=226)$} \\
\hline Dizziness & $109(48.2 \%)$ \\
\hline Diarrhea & $89(38.4 \%)$ \\
\hline Nausea & $68(30.1 \%)$ \\
\hline Feeling your heart pound or race & $51(22.6 \%)$ \\
\hline Sweating & $48(21.2 \%)$ \\
\hline Constipation & $48(21.2 \%)$ \\
\hline Shortness of breathing & $43(19.02 \%)$ \\
\hline Indigestion & $38(16.8 \%)$ \\
\hline Fainting & $30(13.3 \%)$ \\
\hline \multicolumn{2}{|l|}{ Home remedies used to relief menstrual pain $(n=226)$} \\
\hline Drink hot liquids & $128(56.6 \%)$ \\
\hline Rest & $113(50 \%)$ \\
\hline Hot application & 77 (34. $1 \%)$ \\
\hline None & $36(15.9 \%)$ \\
\hline Massage & $34(15.04 \%)$ \\
\hline Any form of exercise (eg, walking) & $32(14.2 \%)$ \\
\hline Herbs & $22(9.7 \%)$ \\
\hline \multicolumn{2}{|l|}{ Pain pattern to the analgesic use $(n=|4|)$} \\
\hline No relief & $18(12.8 \%)$ \\
\hline Minimal relief & $20(14.2 \%)$ \\
\hline Complete relief & $26(18.4 \%)$ \\
\hline Mild relief & 77 (54.6\%) \\
\hline
\end{tabular}

Note: Data are presented as $n(\%)$. menstruation were omitted and thus a mean frequency of $28.83 \pm 4.24$ days was found. The mean duration of the menstrual flow was $5.21 \pm 1.72$ days, with a minimum of 2 days and a maximum of 9 days. Regarding the amount of menstrual flow, $81.04 \%$ of women had an average flow, whereas $16.36 \%$ had heavy flow, and only $2.6 \%$ had spotting. No significant negative correlation ( $r=-0.048, p=0.438$ ) was found between the duration and amount of menstrual flow.

Based on the regularity of menstruation, no significant difference was found with respect to menarche age $(p=0.172)$, whereas a significant difference was found in the amount of menstrual flow and incidence of dysmenorrhea $(p=0.004$ and $0.03)$, respectively.

Regarding pain during menstruation, 226 participants (84.01\%) had dysmenorrhea, whereas 43 (15.99\%) had no dysmenorrhea. The 43 participants who reported having no pain during menstruation were not required to answer any further questions. Of the 226 participants with dysmenorrhea, $140(61.95 \%)$ reported pain in every menstrual cycle and $86(38.05 \%)$ reported pain only in some cycles. When stratifying participants based on the incidence of menstrual pain, significant difference was noted in terms of menstrual regularity, and the length of the menstrual flow, as presented in Table 2 .

A total of 121 participants $(53.5 \%)$ had dysmenorrhea since their menarche, whereas $31(13.7 \%)$ could not recall the time when such symptoms started. Forty-seven participants (20.8\%) reported having dysmenorrhea for several years prior to the study (mean, 4.2 years), whereas $27(11.9 \%)$ reported having pain for several months prior to the study (mean, 7.5 months). With regard to the day when the pain starts, $49.1 \%, 31.9 \%$, and $19 \%$ of participants reported starting feeling pain on the first day of the menstrual flow, 1 day before the menstrual flow, and $>2$ days before the menstrual flow, respectively. On average, pain lasted 2.07 \pm 0.89 days.

Regarding pain severity, abdominal and back pain showed the highest median VAS scores (5.00) (Table 3). Most women

Table 2 Prevalence of menarche, regular cycles, duration, and amount of menstrual cycle based on the presence of menstrual pain

\begin{tabular}{|c|c|c|c|c|c|}
\hline \multicolumn{2}{|c|}{ Menstrual cycle characteristics } & $\begin{array}{l}\text { Participants with } \\
\text { dysmenorrhea }(n=226)\end{array}$ & $\begin{array}{l}\text { Participants without } \\
\text { dysmenorrhea }(n=43)\end{array}$ & t-value & p-value \\
\hline \multicolumn{2}{|c|}{ Menarche (age, years), mean $( \pm S D)$} & $12.9(1.6)$ & $12.95(1.5)$ & 0.37 & 0.71 \\
\hline \multicolumn{2}{|l|}{ Regular cycle n (\%) } & $166(73.4 \%)$ & $38(88.3 \%)$ & & $0.02^{*, a}$ \\
\hline \multicolumn{2}{|c|}{ Length of menses flow (days), mean $( \pm S D)$} & $5.1(1.2)$ & $5.6(1.2)$ & 2.45 & $0.02 *$ \\
\hline \multirow[t]{3}{*}{ Amount of menses } & Drops & $5(2.2 \%)$ & $\mathrm{I}(2.3 \%)$ & \multirow{3}{*}{-0.11} & \multirow{3}{*}{0.92} \\
\hline & Average & $175(77.4 \%)$ & $35(81.4 \%)$ & & \\
\hline & Heavy & $37(16.3 \%)$ & $7(16.2 \%)$ & & \\
\hline \multicolumn{2}{|c|}{ Length of menstrual cycle (days), mean $( \pm S D)$} & $29.1(4.4)$ & $27.6(3.9)$ & -1.89 & 0.06 \\
\hline
\end{tabular}

Note: ${ }^{*} p<0.05$ is considered significant. ${ }^{a}$ Mann - Whitney $U$ test with $z$ value $=-2.32$.

Abbreviation: SD, standard deviation. 
Table 3 VAS for different locations in the body

\begin{tabular}{llll}
\hline Pain location & Mean $( \pm \mathbf{S D})$ & Median & IQR $(Q 3-Q \mathbf{l})$ \\
\hline Abdominal & $4.76(3.12)$ & 5.00 & $7.00-2.00$ \\
Back & $5.24(5.64)$ & 5.00 & $7.00-3.00$ \\
Breast & $\mathrm{I} .41(2.28)$ & 0.00 & $3.00-0.00$ \\
Inner thighs & $3.07(3.18)$ & 2.00 & $5.50-0.00$ \\
Knees & $2.04(2.89)$ & 0.00 & $4.00-0.00$ \\
Hips & $2.23(2.93)$ & 0.00 & $5.00-0.00$ \\
Headache & $2.31(2.79)$ & 1.00 & $4.00-0.00$ \\
\hline
\end{tabular}

Abbreviations: VAS, visual analog scale; SD, standard deviation; IQR, interquartile range.

(91.2\%) did not consult a physician for menstrual pain, whereas $8.8 \%$ did. With regard to pharmacological control of dysmenorrhea, $62.4 \%$ of participants used analgesics, whereas $37.6 \%$ did not. Information regarding the change in pain pattern is provided in Table 1. No significant correlation ( $r=-0.079, p=0.25$ ) was found between analgesic intake and pain relief. Finally, $73.5 \%$ of participants reported that dysmenorrhea caused limitations in their daily activities. Nevertheless, $90.7 \%$ of participants never missed exams, with $46.5 \%$ never missing a university day, and $48.7 \%$ reported poor satisfaction with their academic performance because of dysmenorrhea.

\section{Discussion}

The aim of this study was to explore the prevalence of PD among a group of college female students. Among the 269 women who submitted their responses to the questionnaire, a high prevalence $(84.01 \%)$ of painful menstruation was found, in quantitative agreement with the report by Grandi et $\mathrm{a}^{22}$ and with observations from other previous studies. ${ }^{8,10,14,15}$ While other studies have reported a lower prevalence of $\mathrm{PD},{ }^{11,13,17}$ the findings of the present survey are within the range of $20 \%-90 \%$ reported worldwide. ${ }^{13}$ The variations in reported prevalence of dysmenorrhea are likely related to differences in data collection methods, cultural background, and geographical location. ${ }^{23}$ The present findings indicate a higher prevalence than that reported by three previous studies in Egypt, ${ }^{18,20,21}$ but are similar to the observations of Osman and El-Houfey, ${ }^{19}$ which raises concerns regarding the impact of the study level and major on developing dysmenorrhea.

The mean age at menarche was $12.86 \pm 1.43$ years, which is consistent with the findings from previous studies. ${ }^{8,12,15}$ Young girls at menarche were reportedly more likely to experience dysmenorrhea. ${ }^{24}$ However, no relation $(r=-0.013, p=0.83)$ was found between dysmenorrhea and menarche age, which is consistent with observation from several other reports. ${ }^{9}, 13,15$

In addition, no significant correlation between the duration and amount of menstrual flow was revealed, which is consistent with previous observations. ${ }^{15,25}$
Interestingly, in the present cohort, $60.59 \%$ of the participants reported regularly engaging in physical activities, with no significant correlation between physical activity levels and incidence of dysmenorrhea and no significant difference between physically active and sedentary participants with respect to the incidence and severity of pain during menstruation. Since the questionnaire did not explore the aspect of physical activity further, this lack of association between physical activity levels and menstrual pain may not be representative. While health agencies, clinicians, and women have anecdotal beliefs that exercise is beneficial for reducing dysmenorrhea, ${ }^{26}$ further studies with high scrutiny and evidence-based findings are needed to validate the effectiveness of physical exercise in alleviating menstrual pain.

Among the participants, the mean duration of menstrual pain was $2.07 \pm 0.95$ days, with the majority of responses (49.1\%) indicating that pain starts on the first day of menstrual flow. Generally, pain and other menstruation-associated symptoms appear immediately before or concurrently with the menstrual flow and resolve within the first $24-48$ hours of menstrual flow. ${ }^{27,28}$

In the present survey, pain typically occurred in the lower abdomen, back, and inner thighs and was associated with dizziness, diarrhea, and nausea as somatic symptoms during the menstrual cycle. Previous reports mentioned the same areas of pain and associated somatic symptoms in a high proportion of cases. ${ }^{29}$ Lower abdominal pain is due to increased prostaglandin levels, which were found to be higher in the menstrual blood samples of women with PD than in the samples from eumenorrheic women..$^{30}$ Elevated prostaglandin levels cause four contraction abnormalities that occur alone or in combination, including elevated basal tone $(>10 \mathrm{mmHg}),{ }^{31}$ elevated active pressure $(>120 \mathrm{mmHg}$, often $>150-180 \mathrm{mmHg}$ ), increased number of contractions per 10 minutes ( $>4$ or 5 ), and non-rhythmic or uncoordinated uterine contractions. These abnormalities lead to poor uterine reperfusion and oxygenation, resulting in pain. ${ }^{28}$

Somatic symptoms such as nausea, vomiting, and diarrhea are similar to the adverse effects of prostaglandins and occur in $\geq 60 \%$ of dysmenorrheic women, ${ }^{28}$ which is consistent with the present findings but not with observations from certain previous studies, which reported low rates of altered bowel habits and gastrointestinal symptoms during menses in secondary school ${ }^{15}$ and university students. ${ }^{32}$ It was found that mood changes, fatigue, anxiety, and abdominal bloating were the most commonly reported complaints. Wong and $\mathrm{Khoo}^{33}$ reported that irritability, mood swings, and tension were the most frequently reported affective symptoms, in addition to 
fatigue and menstrual cramps. Mood changes, pain, and gut motility may share similar pathophysiological mechanisms, including regulation via serotonin, which is recognized as an important neurotransmitter mediating affective symptoms experienced during menstruation. ${ }^{34}$ Emotional symptoms occurring in conjunction with gastrointestinal symptoms are a common perimenstrual manifestation, indicating the potential intersection of brain, gut, and hormonal pathways. Fatigue, depression, and anxiety are reportedly very common and significantly associated with multiple gastrointestinal symptoms in both menstrual cycle phases. ${ }^{35}$ With regard to sleep pattern changes, dysmenorrhea has been found to significantly decrease subjective sleep quality, sleep efficiency, and duration of rapid eye movement sleep, but not the duration of slow-wave sleep. ${ }^{36}$

In the present cohort, the participants' main source of knowledge regarding menstruation was their mothers (73.6\%), which is consistent with observations from many other studies. ${ }^{6,11,12,33}$ The results showed that $11.2 \%$ of the participants acquired menstruation-related knowledge on their own, with a very small percentage seeking a physician/ nurse or friend/sibling for discussing the topic of menstruation. Hence, health awareness and education efforts should be focused on mothers, siblings, and friends, to ensure that accurate information is delivered regarding the menstrual cycle and to avoid misconceptions perpetuated by lack of information. Such efforts are expected to help girls and women cope with menstruation-related problems and to encourage positive attitudes toward menstruation. ${ }^{33}$

With regard to analgesic use for controlling dysmenorrhea, $62.4 \%$ of participants reported mostly using nonsteroidal anti-inflammatory drugs (NSAIDs), with $87.2 \%$ achieving minimal to complete pain relief. NSAIDs were reported to be significantly more effective than a placebo for pain relief in women with dysmenorrhea. ${ }^{37}$ The study findings indicate higher use of analgesics compared with that reported in previous studies, ${ }^{22,38}$ which mention the rates of $55 \%$ and $54 \%$. The data imply that discrepancies are related to the lack of further investigation into the dose and frequency of analgesic use. The reduced rate of medical consultation noted in this study is consistent with previous observations $\mathrm{s}^{8,11,12}$ and raises an important concern regarding the use of self-prescribed analgesics and the attitude to avoid seeking medical advice from health care professionals.

Both the present survey and previous studies ${ }^{7,8,12,27,39}$ indicate that self-treatment or home-based treatments are commonly considered to relieve dysmenorrhea. There seems to be a contradiction regarding the most effective remedy.
Specifically, the present cohort indicated that drinking hot liquids is the most effective remedy, whereas Akin et $\mathrm{al}^{40}$ showed that hot-pack application was the most commonly used remedy and may be as effective as ibuprofen, with the combination of hot-pack application and ibuprofen providing relief much faster. ${ }^{40}$ On the contrary, Al Asadi and Abdul Qadir ${ }^{15}$ reported that hot-pack application is the least common method used to control dysmenorrhea.

Furthermore, the college students with PD experienced the most pronounced limitation in daily activities, whereas absenteeism was least affected by PD (16.8\%). These findings are in line with previous observations ${ }^{8,12}$ that absenteeism due to dysmenorrhea occurred in $19 \%$ and $18.1 \%$ of women with PD and contradict the concept that dysmenorrhea is the leading cause of recurrent short-term school and work

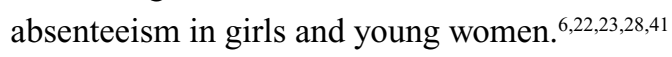

This discrepancy regarding school absenteeism rates may be related to the variability in cultural perceptions and responses to pain. ${ }^{42}$ In addition, Wong ${ }^{12}$ and Al Asadi and Abdul Qadir ${ }^{15}$ reported that PD had the highest impact on the level of concentration in class, which contradicts the observations of previous ${ }^{23}$ and present studies. With respect to missing exam, $90.7 \%$ of participants never missed an exam because of dysmenorrhea, which may be related to the fact that the participants were recruited from among the students of a clinical-based study program undertaken at a government institute with strict rules regarding attendance in class and exams. ${ }^{8}$

The limitations of this study were related to using selfreported questionnaire and to the fact that the responses to some questions (eg, regarding the level of physical activity and analgesic dose) were not investigated further. Moreover, the participants assumed that pain was due to PD. Finally, this a single-center study, and its conclusions should be verified in multicenter studies with a larger and more various sample population.

\section{Conclusion}

It can be concluded that dysmenorrhea is highly prevalent among female college students in Egypt and that dysmenorrhea occurs since their menarche. However, it is very concerning that, despite the high prevalence of PD, the affected students rarely sought medical consultation. Dysmenorrhea often associated with limitations in daily activities, and the affected students expressed poor satisfaction with their academic performance during the periods when they exhibited symptoms. These findings are useful to responsible authorities (eg, student affairs department, program coordinators, 
and student counselors) for developing improved and more holistic strategies to handle dysmenorrhea and promote more effective coping behaviors. In addition, it is recommended that a team of multidisciplinary health care providers should be involved in managing dysmenorrhea.

\section{Disclosure}

The authors report no conflicts of interest in this work.

\section{References}

1. Ali TS, Rizvi SN. Menstrual knowledge and practices of female adolescents in urban Karachi, Pakistan. J Adolesc. 2000;33:531-541.

2. Esimai O, Esan GO. Awareness of menstrual abnormality amongst college students in urban area of Ile-Ife, Osun state, Nigeria. Indian J Community Med. 2010;35:63-66.

3. Avasarala AK, Panchangam S. Dysmenorrhea in different settings: are the rural and urban adolescent girls perceiving and managing the dysmenorrhea problem differently? Indian J Community Med. 2008; 33(4):246-249.

4. Emans SJ, Laufer RL, Goldstein DP. Pediatric \& Adolescent Gynecology. 5th ed. Philadelphia, PA: Lippincott, Williams \& Wilkins; 2005.

5. Twigg J. Dysmenorrhea. Curr Obstet Gynecol. 2002;12:341-345.

6. O'Connell K, Davis AR, Westhoff C. Self-treatment pattern among adolescent girls with dysmenorrhea. J Pediar Adolesc Gynecol. 2006; 19:285-289.

7. Lee LK, Chen PC, Lee K, Kaur J. Menstruation among adolescent girls in Malaysia: a cross sectional school survey. Singapore Med J. 2006; $47: 869-874$.

8. Potal A, Celik H, Gurates B, et al. Prevalence of primary dysmenorrhea in adult female university students. Arch Gynecol Obstet. 2009;279:527-532.

9. Unsal A, Ayranci U, Tozun M, Arslan G, Calik E. Prevalence of dysmenorrhea and its effect on quality of life among a group of female university students. Ups J Med Sci. 2010;115(2):138-145.

10. Habibi N, Huang M, Gan W, Zulida R, Safavi SM. Dysmenorrhea and factors associated with its intensity among undergraduate students: a cross-sectional study. Pain Manag Nurs. 2015;16(6):855-861.

11. Kumbhar S, Reddy M, Sujana B, Roja RK, Balkrishna C. Prevalence of dysmenorrhea among adolescent girls (14-19 yrs) of Kadapa District and its impact on quality of life: a cross sectional study. Natl J Community Med. 2011;2(2):265-268.

12. Wong L. Attitudes towards dysmenorrhea, impact and treatment seeking among adolescent girls: a rural school-based survey. Aust J Rural Health. 2011;19:218-223.

13. Burnett MA, Antao V, Black A, et al. Prevalence of primary dysmenorrhea in Canada. J Obstet Gynaecol Can. 2005;27(8):765-770.

14. Al-Kindi R, Bulushi A. prevalence and impact of dysmenorrhea among Omani high school students. Sultan Qaboos Univ Med J. 2011; 11(4):485-491.

15. Al Asadi J, Abdul Qadir R. Dysmenorrhea and its impact on daily activities among secondary school students in Basra, Iraq. $J$ Fac Med Baghdad. 2013;55(4):339-344.

16. Santina T, Wehbe N, Ziade F. Exploring dysmenorrhea and menstrual experiences among Lebanese female adolescents. EMHJ 2012; 18(8):857-863.

17. Ibrahim N, AlGhamdi M, Al-Shaibani A, et al. Dysmenorrhea among female medical students in King Abdulaziz University: prevalence, predictors and outcome. Pak J Med Sci. 2015;31(6):1312-1317.

18. Mohamed E. Epidemiology of dysmenorrhea among adolescent students in Assiut City, Egypt. Life Sci J. 2012;9(1):348-353.
19. Osman H, El-Houfey A. Prevalence of dysmenorrhea and its impact on quality of life among nursing students at Assuit University, Egypt. IOSR-JNHS. 2016;5(1):8-16.

20. El-Gilany A, Badawi K, El-Fedawy S. Epidemiology of dysmenorrhea among adolescent students in Mansoura, Egypt. East Mediterr Health J. 2005;11(1):155-163.

21. Mohamed H, Mansour S. The effect of dysmenorrhea on quality of life of technical secondary schools girls. Med J Cairo Univ. 2013;81(2): $83-90$.

22. Grandi G, Ferrari S, Xholli A, et al. Prevalence of menstrual pain in young women: what is dysmenorrhea? J Pain Res. 2012;5:169-174.

23. Banikarim, C, Chacko R, Kelder H. Prevalence and impact of dysmenorrhea on Hispanic female adolescents. Arch Pediatr Adolesc Med. 2000;154:1226-1229.

24. Omidvar SH, Begum KH. Menstrual pattern among unmarried women from south India. J Nat Sci Biol Med 2011;2(2):174-179.

25. Parveen N, Majeed R, Rajar M. Familial predisposition of dysmenorrhea among medical students. Pak J Med Sci. 2009;25(5):857-860.

26. Daley A. The role of exercise in the treatment of menstrual disorders: the evidence. Br J Gen Pract. 2009;59(561):241-242.

27. Hillen I, Grbavac L, Johnston J, Straton JA, Keogh JM. Primary dysmenorrhea in young Western Australian women: prevalence, impact and knowledge of treatment. J Adolesc Health. 1999;25:40-45.

28. Dawood M. Primary dysmenorrhea: advances in pathogenesis and management. Obstet Gynecol. 2006;108(2):428-441.

29. Ylikorkala O, Dawood MY. New concepts in dysmenorrhea. Am J Obstet Gynecol. 1978;130:833-847.

30. Pickles VR, Hall WJ, Best FA, Smith GN. Prostaglandin in endometrium and menstrual fluid from normal and dysmenorrhoeic subjects. JObstet Gynaecol Br Commonw. 1965;72:185-192.

31. Csapo AI, Pinto-Dantas CR. The cyclic activity of the non-pregnant human uterus: a new method for recording intrauterine pressure. Fertil Steril. 1966;17:34-38.

32. Kane SV, Sable K, Hanauer SB. The menstrual cycle and its effect on inflammatory bowel disease and irritable bowel syndrome: a prevalence study. Am J Gastroenterol. 1998;93(10):1867-1872.

33. Wong LP, Khoo EM. Menstrual-related attitudes and symptoms among multi-racial Asian adolescent females. Int J Behav Med. 2011;18(3): 246-253.

34. Whitehead WE, Cheskin LJ, Heller BR, et al. Evidence for exacerbation of irritable bowel syndrome during menses. Gastroenterology. 1990;98(6):1485-1489.

35. Bernstein M, Graff L, Avery L, Palatnick C, Parnerowski K, Tarqownik LE. Gastrointestinal symptoms before and during menses in healthy women. BMC Womens Health. 2014;14:14.

36. Baker F, Driver H, Rogers G, Paiker J, Mitchell D. High nocturnal body temperatures and disturbed sleep in women with primary dysmenorrhea. Am J Physiol. 1999;277(6 Pt 1):E1013-E1021.

37. Marjoribanks J, Proctor ML, Farquhar C. Non-steroidal anti-inflammatory drugs for primary dysmenorrhea. Cochrane Database Syst Rev. 2003;4:CD001751.

38. Johnson J. Level of knowledge among adolescent girls regarding effective treatment for dysmenorrhea. J Adolesc Health Care. 1988;9(5): 398-402.

39. Chang T, Chen C. Study of menstrual attitudes and distress among post-menarcheal female students in Hualien County. J Nurs Res. 2009; 17:20-29.

40. Akin M, Weingand K, Hengehold D, Goodale MB, Hinkle RT, Smith RP. Continuous low level topical heat in the treatment of dysmenorrhea. Obstet Gynecol. 2001;97(3):343-349.

41. Klein R, Litt F. Epidemiology adolescent dysmenorrhea. Pediatrics. 1981;68(5):661-664.

42. Wenger AF. Cultural meaning of symptoms. Holist Nurs Pract. 1993; $7(2): 22-35$. 
The Journal of Pain Research is an international, peer reviewed, open access, online journal that welcomes laboratory and clinical findings in the fields of pain research and the prevention and management of pain. Original research, reviews, symposium reports, hypothesis formation and commentaries are all considered for publication
The manuscript management system is completely online and includes a very quick and fair peer-review system, which is all easy to use. Visit http://www.dovepress.com/testimonials.php to read real quotes from published authors.

Submit your manuscript here: https://www.dovepress.com/journal-of-pain-research-journal 